\title{
The legalisation of cannabis: A security-vetting dilemma
}

\author{
Piet Bester ${ }^{l}$ and Sonja Els ${ }^{2}$ \\ Stellenbosch University
}

\section{Introduction}

During 1996, the South African Intelligence Community issued the Minimum Information Security Standards (MISS), which inter alia address the protection of classified information. The MISS provide the principles, standards and procedures to be followed by all South African government agencies for the protection of official resources. ${ }^{3}$ This includes the granting of different types and levels of security clearances by the South African government to provide employees and contractors access to classified information. The decision to grant a person access to classified information is based on such individual's security competence. This is an indication of the person's ability - based on his or her conduct - to prevent classified material from being disclosed to unauthorised persons, which may potentially prejudice or endanger the security or interests of the employing institution or the state. An applicant for a security clearance may be a prospective employee applying for a post from outside the organisation or an insider who is already in the organisation, often referred to as outsider and insider threats. ${ }^{4}$ The process of determining a person's security competence is referred to as security vetting for new employees, and re-vetting for existing employees who have gone through the vetting process in the past. ${ }^{5}$ In this article, the use of the term 'vetting' includes re-vetting.

Most drugs have an impairment potential, and therefore an individual's involvement with drugs or dependence-forming substances raises a security concern if the drug or substance is illegally used, is in possession - including cultivation, processing, manufacture, purchase, sale or distribution - or if the substance used causes the affected individual to be diagnosed as drug-dependent or as being an abuser by a registered health care professional. ${ }^{6}$ These may lead to an unfavourable determination of the affected individual's security competence. The improper or illegal involvement with drugs therefore raises questions about an individual's security competence and his or her willingness and/or ability to protect classified information and/or state assets.

It is common knowledge that cannabis has an impairment potential. The use of cannabis was illegal in South Africa until September 2018 when the Constitutional Court partially decriminalised cannabis in the matter of Minister of Justice and Others $v$. Prince \& Others when an adult uses, possesses or grows cannabis in private or for personal consumption. ${ }^{7}$ Organisations that require their personnel to undergo security vetting, therefore raise the question whether the legalisation of cannabis use has overlooked the risk that was previously implied with cannabis use. 
Facing the dilemma of the use of cannabis by an employee, the security-vetting institution must judge whether it is a risk, whether it is a manageable risk, and ultimately how security personnel and/or line managers should supervise and monitor the person. The issue is exacerbated furthermore by the estimation that the South African cannabis consumption is twice the world norm. ${ }^{8}$

An overview of the relevant South African security-vetting literature indicates that little to no scholarly attention has been paid to the issue of the legalisation of cannabis and how it will influence the vetting decisions of an applicant's security competence. This leads to what can be referred to as a security-vetting dilemma that denotes a situation in which one's efforts to secure the state may lead to an infringement of the rights of the individual.

This security-vetting dilemma can be formulated as follows: How does the legalisation of cannabis influence vetting decisions on the security competence of employees? This specifically refers to employees who, for example, consume cannabis at or before work, or those who may show up at work impaired due to the use of cannabis.

This conundrum necessitated the present research to gain more insight from an academic perspective and to provide some guidelines to practitioners who have to make vetting decisions in relation to the use of cannabis. Vetting decision-makers' knowledge on the security implications of cannabis consumption is vital for the development of vetting policy, as it is widely known that the greatest security risk to an organisation comes from the people within. ${ }^{9}$ Subsequently, this article briefly discusses the relevant securityvetting terms, such as 'security vetting' and 'security risk'; critically analyses existing South African cannabis-related legislation; explores cannabis as substance and its impact on the individual; and subsequently analyses its impact on the workplace. This is followed by a discussion on the security-vetting implications of cannabis use and the management thereof in the workplace. The study is concluded with a summary and recommendations for vetting institutions.

\section{Security vetting and security risk}

When one wants to gain insight into the concepts 'security vetting' and 'security risk' one has to start with the Minimum Information Security Standards (MISS).

Mdluli argues that security vetting is of the utmost importance to the security of the state, especially to the Department of Defence, as much of the security of the state depends on the integrity and reliability of its civil servants. ${ }^{10}$ She argues that security vetting is meant to establish the security competence of the applicant, which relates to integrity and reliability regarding the handling of classified information. ${ }^{11}$ South Africa's MISS define security vetting as "a systematic process of investigation, followed in determining the security competency of a person". ${ }^{12}$ This is done to counter subversion, treason, sabotage and terrorism aimed at or against personnel, strategic installations or resources of the Republic of South Africa. ${ }^{13}$ Security vetting is further described as a process in which individuals are scrutinised by means of background investigations that aim to determine whether past behaviour of an individual is a concern for future reliability, honesty and integrity. ${ }^{14}$ The integrity of individuals includes inter alia a sense 
of duty, dedication, reliability, adherence to human rights, obedience, honesty, ability to manage finances, responsibility, moral values and averting security vulnerabilities. ${ }^{15}$ The security-vetting process is measurable, and when approved, is referred to as the security competence of an individual. Other states, such as Israel, refer to the concept 'security suitability' rather than security competence. ${ }^{16}$

In essence, security vetting and the subsequent determination of a person's security competence are required to consider whether such person is a security risk. In the counter-intelligence context, Wiese states that a person can be viewed as a security risk when his or her personality traits, needs, behaviour, ideological persuasion or extreme sensitivity in terms of past deeds can be used to persuade him or her, by whatever means, to cooperate with an unauthorised individual or organisation to divulge secrets of his or her employer, or to divulge secrets to an unauthorised individual or organisation of his or her own accord. ${ }^{17}$ Although not pertinently stated, one could also include the protection of co-workers and not only the state or its institutions or assets. Molapo observes that security-screening investigations contribute to ensure that employees of government departments conduct themselves in a manner that will not endanger or compromise the image of the individual or, especially, the image of the particular department. ${ }^{18}$ Mdluli states that the security competence of an individual is normally measured against the criteria of susceptibility to extortion or blackmail, integrity, amenability to bribes, loyalty, susceptibility to being compromised or influenced due to compromising behaviour, integrity and acts endangering security. ${ }^{19}$ The above emphasise the exposing nature of security vetting. This view is supported by the United Kingdom's former Defence Vetting Agency, which stated that the process will sometimes reveal character flaws or circumstances that result in serious security risks. ${ }^{20}$ Consequently, security vetting could expose how cannabis use influences an individual's security competence.

At the end of the process, a vetting decision is made with respect to a person's eligibility to access classified information. This is a discretionary security decision based on whether the applicant constitutes a security risk. Since the context of security vetting and security risk is being discussed, the next part takes a closer look at cannabis.

\section{Cannabis as substance}

An overview of the relevant literature indicates that cannabis use could be both beneficial and harmful. ${ }^{21}$ This dualism of both benefits and harm is seen in the following quote, which clearly illustrates the competing claims amongst academics and scientists that contribute to the security-vetting dilemma referred to above.

[C]annabis use by young adults and vulnerable individuals across the lifespan can be a contributory cause of: cannabis dependence syndrome; schizophreniform psychoses; anxiety and depressive disorders; acute and perhaps chronic cognitive impairment, and structural and functional changes in brain pathways implicated in reward, learning and addiction [...] have neuroprotective properties and can be used to treat anxiety, depression, sleep disorders, pain, neurological disorders and dependence on various drugs including cannabis. ${ }^{22}$ 
Like alcohol and other drugs, the use of cannabis cannot be generalised. Consequently, the use of cannabis, as evaluated by a security-vetting officer and/or decision-maker, is diverse and covers more than the assumed single mode and product of use, which is usually the smoking of the plant, and includes other forms of use, such as concentrates, edibles, blunts and vaporisers. ${ }^{23}$ It is therefore important to discuss the effects of cannabis.

\section{The effects of cannabis}

The United Nations' World Drug report for 2020 reveals that in 2018, cannabis was the most widely used substance globally. In South Africa, an estimated 3,7 per cent of the country's population uses cannabis. ${ }^{24}$ Furthermore, cannabis is the most prevalent drug for which criminals involved in property and violent crimes tested positive. Singh refers to a recent study released by the Soul City Institute in Johannesburg, which ranks South Africa among the countries with the highest levels of drug abuse globally. ${ }^{25}$ The study, furthermore, reveals that close to 10 per cent of the population starts experimenting with drugs at the age of $13 .{ }^{26}$ Prior to its legalisation, cannabis was the most regularly used "illicit" substance amongst the South African youth. ${ }^{27}$ These statistics and frequencies support the notion to discuss the effects of cannabis.

The use of cannabis has a number of health implications, such as the development of cannabis use disorder (CUD), respiratory illness, development and exacerbation of psychiatric disorders and altered brain development, among others. ${ }^{28}$ Moreover, evidence from worldwide population data indicates that approximately 6,5 per cent of cannabis users have a CUD. ${ }^{29}$ The effect of cannabis is also determined by the potency of the content of delta-9-tetrahydrocannabinol $(\Delta 9-\mathrm{THC})$, the psychoactive key ingredient, in relation to cannabidiol (the $\triangle 9-\mathrm{THC}$ to $\mathrm{CBD}$ ratio).

The use of concentrates is especially alarming as they demonstrate extreme potency of up to 80 per cent $\Delta 9$-THC. This results in a high level of intoxication with many long-term physiological, cognitive and psychological effects with an increase in CUD with signs and symptoms, such as temporary problems with perception and cognitive functioning, disinhibition, spontaneous laughing, disturbances to vision, thought and memory, coordination loss with confusion, dry mouth and sleepiness. ${ }^{30}$ Cognitive impairment, such as decreased working memory function, occurs in adolescent or early-onset cannabis users. ${ }^{31}$ 'Working memory' refers to the ability to manipulate small amounts of information to achieve a particular goal. It also forms part of the broader executive functioning that selects, initiates, monitors and modulates other cognitive activities during daily functioning. These activities include, but are not limited to, educational achievement, emotional regulation, behavioural inhibition, and quality of decision-making. Moreover, research indicates that earlier age of starting to consume cannabis, combined with high frequency and high potency cannabis use, and sustained uses of synthetic cannabinoids over time, correlate with a higher likelihood to develop potentially severe and persistent impairment of executive functions. ${ }^{32}$ Research by Van der Steur et al. supports these findings as they found that frequent cannabis consumption, especially on a daily basis, and the consumption of high-potency varieties with a high concentration of $\triangle 9-\mathrm{THC}$ are both associated with a higher risk of developing 
psychosis. ${ }^{33}$ A Swedish study revealed that a relative risk for schizophrenia among high consumers of cannabis indicated a 95 per cent confidence interval in comparison with cannabis non-users pointing to a relationship between the level of cannabis consumption and schizophrenia. ${ }^{34}$ It is, however, important to note that cannabis-related cognitive deficits can be overcome after long periods of abstinence. ${ }^{35}$

In addition, the legalisation of recreational cannabis use is likely to increase the incidence of use amongst current users as well as the number of new users, increasing the risk of developing a dependence syndrome similar to that of alcohol and other drugs. ${ }^{36}$ Cannabis is often a gateway to hard drugs. ${ }^{37}$ It is, therefore, important to consider the issue of the recreational use of cannabis versus the medicinal use of the substance.

\section{Recreational vs medicinal use}

People who use cannabis for recreational purposes tend to use it mainly for its psychoactive effects. $\triangle 9$-THC, one of the chemicals found in cannabis, creates a form of euphoria for most people. Cannabis also creates an alternative mental state in which the user can literally recreate his or her own reality. ${ }^{38}$ As a result - and alluded to above - at individual level, cannabis influences the way an individual experiences his or her environment, emotional state, thinking, memory, decision-making, coordination, reaction time, and judgement, causing impairment. In South Africa with its high levels of HIV, AIDS and tuberculosis, using cannabis also indirectly compromises individuals' compliance with treatment regimes. ${ }^{39}$ Moreover, spending significant amounts of money on cannabis may influence the financial state of individuals, which may lead to petty crime in the workplace.

Amongst the public, there is still a debate on the detrimental and potentially therapeutic effect of cannabis on the brain and related behaviour. Singh comments extensively on the medicinal use of cannabis, which dates back to the ancient Roman era where cannabis was used as relief for medical conditions, such as gout pains and rheumatism. ${ }^{40} \mathrm{Singh}$ concludes that in the modern world, where technology can identify the pharmacological composition of cannabis, it is clear that cannabis, as with all medicines, has advantages and disadvantages for medicinal use. ${ }^{41}$ Many countries, with California in the United States as the forerunner, advocate educated and knowledgeable recommendations for the medicinal uses of cannabis. ${ }^{42}$

Various global studies reveal scientific evidence of advantages of the use of cannabis as medicine. Examples of such studies are the following: ${ }^{43}$

- the American Institute of Medicine (1999), which proposes the development of a medical cannabinoid inhaler used under stringent medical protocols;

- a study by Chong (2006), which revealed use of cannabis for the relief of neuropathic pain and muscular spasms for patients with multiple sclerosis;

- a scientific study by Solowiji (2018), which found enhanced therapeutic effects of cannabis in a compromised brain; and

- $\quad$ a study by the University of the Free State in South Africa (2018), which 
proposes the use of cannabis to assist with the regulation of insulin action on breast cancer cells of patients with diabetes.

In terms of the medicinal use of cannabis, the jury is still out on the effectiveness of the drug for the treatment of certain illnesses. For example, in South Africa, only one cannabis drug has been approved for clinical use, although, when prescribed as a medication, it should be treated differently compared to any other intoxicating medication. ${ }^{44}$

Cannabis not only influences the users themselves, but it also has social implications such as harm to others, including injuries due to violence. ${ }^{45}$ From the above, it is clear that cannabis has a physiological, cognitive and psychological effect on the individual. As one is dealing with the individual during the security-vetting process, it is important to take note of the factors influencing the effect that cannabis use has on an individual.

\section{Factors determining the effect of cannabis}

There are several factors that determine the effect cannabis has on its users. The first is the frequency of use. More intensive use of cannabis increases the odds for adverse consequences among users. ${ }^{46}$ To illustrate this point, a growing number of studies indicate that restlessness, irritability and anxiety, which may be associated with aggression, follow within 24 to 48 hours after the abrupt cessation of frequent cannabis use. ${ }^{47}$ Moreover, studies in high-risk populations indicate that more frequent users of cannabis show signs of an increased propensity for violence. ${ }^{48}$ Although frequency of use is important, it is essential that additional factors be considered, such as the quantity and type of product used and the effect that its use has on the individual.

In addition to frequency, the duration of the use of the substance is important. The chronic use of cannabis could lead to respiratory and cardiovascular toxicity and the development of cannabinoid hyperemesis syndrome. This is mainly a health issue and not related to security vetting, but it could lead to certain psychiatric conditions, which may have an adverse effect on an individual's security competence. ${ }^{49}$ Psychiatry-related conditions relate to experiencing anxiety, paranoia, psychotic disorders and loss of cognitive ability. Based on findings from recent studies, 13 per cent of schizophrenia cases could be linked to cannabis use. ${ }^{50}$ Studies also show that the continuous use of cannabis-based narcotics impairs long-term memory. ${ }^{51}$

In terms of the quantity used, studies indicate that both acute and chronic cannabis intoxication may impair a person's executive functioning (cognitive domain) and in that way, create perceptual distortions, such as interpreting neutral actions as aggressive; impairing the user's ability to suppress aggression; heightening physiological arousal, leading to feelings of anxiety, paranoia and panic, ${ }^{52}$ postulating a positive dose-response relationship.

Furthermore, the concept cannabis load refers to a combination of both frequency and quantity of use, and is used as a single component to measure cannabis use. ${ }^{53}$ This term was constructed by multiplying the values of frequency (number of days per week) and quantity (the number of joints smoked per day). 
In addition to the above, the mode of use and products consumed is another factor to consider, especially in terms of how a person's body absorbs the substance. In this regard, an international study on cannabis use amongst university students, found that 76 per cent of users engaged in the use of products besides the plant itself. This highlights the importance of considering this factor in security competence determinations. ${ }^{54}$ To illustrate this, Hazekamp indicates that cannabidiol (CBD) oil, which is popular in the medicinal administration of cannabis, contains differing concentrations of $\triangle 9$-THC. ${ }^{55}$ Furthermore, using products with high potency (such as concentrates) has the potential to lead to significant increases in impairment, intoxication and the lasting effects of the substance. ${ }^{56}$ For example, due to the high $\triangle 9$-THC potency of the product concentrate, users are more likely to develop tolerance or experience withdrawal. ${ }^{57}$ This is whether or not the cannabis product is organic or synthetic cannabinoids, as synthetic cannabinoids may have more health risks than organic products. ${ }^{58}$

The consequences of how the individual reacts to the product consumed, emphasise that one cannot use a blanket approach when considering the effects of cannabis consumption on individuals. Research has indicated that individuals differ in unobserved ways in terms of their vulnerability to starting and stopping cannabis use and their unobserved mental and physical health frailties. ${ }^{59}$ Research in the Netherlands indicates the physical and mental health effects of cannabis consumption are likely to be small. ${ }^{60}$ Nevertheless, an overview of cannabis-related literature indicates that cannabis use has been associated with various adverse consequences, such as motor vehicle accidents, and an increased risk of psychotic disorders among susceptible individuals. ${ }^{61}$ It is also noteworthy that certain practices during the cultivation of the plants - such as the lighting, use of chemicals, such as insecticides, nutrients and fertiliser - could have different effects on different individuals. ${ }^{62}$ It would thus be safe to state that cannabis use is likely to impair cognition and brain functioning, causing impaired judgement. During the vetting process, it is therefore necessary to obtain information on the kind of cannabis and the effect thereof on the behaviour of the individual. One must determine how each individual reacts in the context of the above-mentioned factors.

A combination of the above factors also contributes to and is supplemented by various categories of users, which are described below.

\section{Categories of users}

A classification system, usable for vetting purposes, is identified in the literature and is referred to as 'classes of users'. These are light plant users, moderate frequency plantbased users, heavy plant users, heavy plant and concentrate users, light plant and edible users, and a high frequency all-product users (plant, concentrate and edible).$^{63}$ Based on an overview of the literature, two additional groups can be added, namely those who use cannabis for medicinal purposes only (prescribed cannabis-related medication) and those who experimented with cannabis, but never became frequent users. Table 1 below summarises these categories of users. 
Table 1: Category of users

\begin{tabular}{|l|l|}
\hline $\begin{array}{l}\text { Experimental } \\
\text { users }\end{array}$ & Only experimented once or twice with the drug \\
\hline $\begin{array}{l}\text { Frequent } \\
\text { recreational users }\end{array}$ & Light plant users \\
\cline { 2 - 2 } & Moderate frequency plant-based group \\
\cline { 2 - 2 } & Heavy plant users \\
\cline { 2 - 2 } & \begin{tabular}{l} 
Light plant and edible users \\
\cline { 2 - 2 } High frequency all-product users (plant, concentrate and edible)
\end{tabular} \\
\hline Medicinal users & $\begin{array}{l}\text { Those using prescribed or over-the-counter cannabis medication } \\
\text { for medicinal purposes only }\end{array}$ \\
\hline
\end{tabular}

Source: Authors' own compilation

It is therefore clear that the consumption of cannabis products has various immediate and long-term positive and negative effects, depending on the frequency, quantity, mode of use and product combined with the category of user and, ultimately, how the individual reacts to the stimulant. It was beyond the scope of the study reported here to determine the harm and benefits of the substance. The aim was rather to discuss the implications of the substance for conduct in the workplace in general and, more specifically, the risk associated with giving a user access to classified information.

\section{The risk}

The combination of factors mentioned above suggests a certain security risk level for a cannabis user. In this regard, the literature indicates that the risk profile of an individual with five episodes of substance use per day differs from someone who uses a small amount once a day. ${ }^{64} \mathrm{~A}$ study concluded that high frequency all-product users reported the highest number of consequences of the use of the substance, ${ }^{65}$ thus, posing a higher risk in terms of manifesting problems related to the use of these products.

Considering the possible impact of cannabis use in the workplace it is important to conduct all risk assessments during the vetting process within the legal framework of South African law.

\section{The legal environment}

Contrary to the private sector, security vetting in the public sector is governed by legislation. Mdluli correctly summarises that three vetting agencies in South Africa have the legal mandate to conduct security vetting in accordance with the National Strategic Intelligence Amendment Bill, 2008. ${ }^{66}$ These agencies are:

- the State Security Agency created in terms of a Presidential proclamation in 2009;

- $\quad$ the intelligence division of the South African Police Service (SAPS) mandated by the Police Act; ${ }^{67}$ and 
- $\quad$ the intelligence division of the South African National Defence Force (SANDF) mandated by the Defence Act, 2002. ${ }^{68}$

Section 37(2) of the Defence Act emphasises the importance of security vetting in that a member or employee may not be enrolled, appointed, promoted, receive a commission or be retained unless he or she has been issued with the appropriate or provisional grade of security clearance by Defence Intelligence. Furthermore, section 38 of the Defence Act authorises the Minister of Defence even to discharge any member or employee not issued with the necessary security clearance. The importance of security vetting, especially in the public domain, can therefore not be overemphasised.

In making a vetting decision where cannabis use by the applicant is considered, the vetting officer needs to be mindful of the legal stance concerning cannabis use. Two landmark court decisions in 2017 set the scene for the lawful production, distribution and use of cannabis in South Africa. ${ }^{69}$ This was followed by a controversial Constitutional Court decision in September 2018 on the constitutionality of certain clauses of the Drugs Act of 1992 and the Medicines Act of $1965 . .^{70}$

It is essential first to consider the history of South African legislation on cannabis use before analysing these developments.

It is well known that wild cannabis has been used for centuries by South African indigenous people for recreational, traditional, medicinal and religious purposes. However, the escalation of drug trafficking and substance abuse in later years resulted in an absolute ban on the dealing, cultivation and possession of cannabis in South Africa. ${ }^{71}$ These prohibitions originated from the international Treaty of Versailles, which required signatory states to establish processes to repress the illicit drug trade of, inter alia, cannabis. Following the signing of this treaty in 1919, South Africa promulgated the Customs and Excise Duties Amendment Act in 1922. This Act prohibited the cultivation, sale, possession and use of cannabis, cocaine and a number of other substances. ${ }^{72}$ In 1924, cannabis was officially added to the international list of habit-forming drugs by the Advisory Committee for the Council of the League of Nations, as part of international law. ${ }^{73}$ Similarly, the use of cannabis was completely criminalised in South Africa in 1928 under the Medical, Dental and Pharmacy Act. ${ }^{74}$ Cannabis prohibition was also included in the Weeds Act in $1937 .{ }^{75}$

Other legislation that prohibits the production, distribution or use of cannabis followed at a steady pace namely the following:

- Medicines and Related Substances Act, $1965 ; 76$

- Pharmacies Act, $1974 ;{ }^{77}$

- Criminal Procedure Act, 1974 (allowing for searches and seizures) $;^{78}$ and

- $\quad$ Drugs and Trafficking Act, $1992 .{ }^{79}$

Furthermore, cannabis was classified as a Schedule 7 substance that is subject to special restrictions and controls. ${ }^{80}$ Among other things, the Drugs and Trafficking Act allowed 
for people found in possession of more than $115 \mathrm{~g}$ of cannabis to be presumed guilty of dealing in the narcotic. In 1995, following the adoption of the Interim Constitution, the Constitutional Court declared this presumption unconstitutional, as it unjustifiably infringed the constitutionally enshrined presumption of innocence. ${ }^{81}$

In order to contextualise the medicinal use of cannabis in South Africa, the Medical Innovation Bill was proposed in 2014. ${ }^{82}$ The aim of the Bill was the legalisation of the use of cannabinoids for medicinal purposes. Although the Bill was rejected by Parliament, the Medical Control Council published license application procedures in 2017 to plant, produce or trade in cannabis for medicinal and educational purposes ${ }^{83}$

\section{Constitutional challenges and the current law on the use of cannabis}

Prior to 1994, the effective judicial protection of human rights was virtually impossible in South Africa. ${ }^{84}$ The 1996 South African Constitution introduced a number of fundamental rights in the Bill of Rights. These fundamental rights referred to basic human rights such as the right to privacy, the right to freedom of religion, the right to human dignity, and the right to freedom and security of the person. However, these rights are not absolute, and a general limitation clause was built into the 1996 Constitution to specify the criteria for the justification of restrictions of the fundamental rights ${ }^{85}$ Rights may therefore be justifiably infringed if the limitation is reasonable and justifiable in an open and democratic society, taking into account the nature of the right, the importance of the purpose of the limitation, and less restrictive means to achieve the purpose of limitation. ${ }^{86}$

During 2001, allegations of 'unjustifiable limitation' of the right to religious freedom, as guaranteed by section 15 of the Constitution, initiated the battle for the legalisation of cannabis in South Africa in a court case.$^{87}$ The appellant, Prince, was refused admission by the Law Society of South Africa due to his two previous convictions for possession of cannabis and his expressed intention to continue using cannabis as a result of his religious beliefs. Prince challenged the decision of the Law Society submitting that the constitutional validity of the prohibition on the use or possession of cannabis was unjustified when motivated by his Rastafarian religion. The use of cannabis is central to the Rastafarian religion. Prince unsuccessfully approached the High Court, the Supreme Court of Appeal, and the Constitutional Court over the next number of years, but was granted no relief. ${ }^{88}$

Prince maintained that his fundamental rights were infringed, and in March 2017, he, together with several other applicants, approached the Western Cape High Court in the 'second Prince case', this time basing the submission on the right of privacy. ${ }^{89}$ The applicants also challenged the constitutional validity of sections 4(a) and (b) as well as section 5(b) of the Drugs and Drug Trafficking Act 140 of 1992 and section 22(10) of the Medicines and Related Substances Act 101 of 1965. The argument was that it was not the state's right to dictate what people may eat, drink and smoke in the privacy of their own homes. ${ }^{90}$ Furthermore, the applicants relied on a judgement made by the Constitutional Court in the case of Bernstein v Bester where it was stated: 
A very high level of protection is given to the individual's intimate personal sphere of life and the maintenance of its preconditions and there is a final untouchable sphere of human freedom that is beyond interference from any public authority. So much so that, in regard to this most intimate core of privacy, no justifiable limitation thereof can take place. But this most intimate core is narrowly construed. This inviolable core is left behind once an individual enters into relationships with persons outside this closest intimate sphere; the individual's activities then acquire a social dimension and the right of privacy in this context becomes subject to limitation. ${ }^{91}$

Singh reports that the applicants also submitted to the court that the distinction between cannabis, tobacco and alcohol is unreasonable and therefore unjustifiably restrict the right of privacy. ${ }^{92}$

The Western Cape High Court ruled that the blanket prohibition on the use of cannabis is unconstitutional, as it impedes on the basic human right of privacy. ${ }^{93}$ Therefore, the criminalisation of home use and cultivation of cannabis by adults, as specified in the Drugs Act of 1992 and the Medicines Act of 1965 is mutatis mutandis unconstitutional. The invalidity of the said legislation was suspended for a period of 24 months to allow Parliament to amend the legislation. The Constitutional Court confirmed the order by the High Court on 18 September 2018, interpreted the right to privacy as being the "right to be left alone", and ruled that the use or possession of cannabis by an adult person "in private for personal consumption" is legal..$^{94}$ The use of cannabis was only "partly decriminalised" as the finding does not affect the laws governing the trading, use and possession of cannabis in public. South Africa was the first country in Africa to decriminalise the use of cannabis partly. ${ }^{95}$ The Constitutional Court has not specified the amount of cannabis that will be deemed lawful for personal consumption in private, and considers it a matter for attention in future legislation. ${ }^{96}$ In this landmark decision, the Constitutional Court also declared section 40(1)(h) of the Criminal Procedure Act (1997) constitutionally invalid. Thus, it is no longer a criminal offence for an adult to use or be in possession of cannabis for personal consumption in private. It is clear that the Constitutional Court does not restrict the use or possession of cannabis to a home or private dwelling. If not properly addressed in future legislation, challenges of implementation may arise in differentiating between private and public for purposes of enforcement. ${ }^{97}$

Following the directive of the Constitutional Court, the draft Cannabis for Private Purposes Bill, 2020 (hereafter the draft 2020 Cannabis Bill) was introduced in the National Assembly. ${ }^{98}$ The opportunity for public comments closed on 30 November 2020, and it is now up to Parliament to consider the content. However, this proposed bill is widely claimed to be inadequate as it ignores any commercial opportunities for cannabis; it fails to accommodate its medicinal uses; and it provides for unreasonable punishments for offenders who exceed the permitted quantities of cannabis. ${ }^{99}$ 
In essence, the draft 2020 Cannabis Bill permits adults to do the following for personal use only:

- $\quad$ possess an unlimited quantity of cannabis seedlings;

- $\quad$ cultivate - in a private place - four flowering cannabis plants per adult;

- $\quad$ possess, in private, $600 \mathrm{~g}$ of cannabis per adult; and

- $\quad$ possess, in private, $100 \mathrm{~g}$ of cannabis in a public place. ${ }^{100}$

The definitions in the draft 2020 Cannabis Bill include the following meanings: ${ }^{101}$

- "Possess in private" means to keep, store, transport, or be in control of cannabis or a cannabis plant, in a manner that conceals it from public view;

- "Private place" means any place, including a building, house, room, shed, hut, mobile home, caravan, boat, or land, to which the public does not have access as of right; and

- "Public place" means any place to which the public has access as of right.

The proposed bill is yet to be finalised and promulgated.

During the adjudicative process of security vetting, the vetting officer needs to be acutely mindful of the constitutional aspects of fundamental rights, as some of these rights will inevitably be affected, directly or indirectly, during the process of security vetting. Any infringements of fundamental rights need to be constitutionally justifiable in the circumstances.

\section{Workplace legislation}

Although not directly related to security vetting per se, Mokwena reports that cannabis use has often been associated with workplace injuries and/or challenges of workplace productivity. ${ }^{102}$ Laurens and Carstens emphasise that the constitutional judgement (second Prince case) does not affect any of the existing statutes that regulate health and safety in workplaces and other risk-sensitive environments. ${ }^{103}$ It is submitted that, even after implementation of the draft 2020 Cannabis Bill, workplace legislation will remain applicable. In this regard, the Occupational Health and Safety Act (OHS Act) (No. 85 of 1993) demands of employers to provide and maintain, as far as possible, a working environment that is safe and without risk to the health of their employees. ${ }^{104}$ The OHS Act and the General Safety Regulations thereof, prohibit the use of any heavy equipment or machines when a person is under the influence of any drug (including cannabis) and employers can, even with prescription medicine use, not allow employees to perform duties where side-effects constitute a threat to the health and safety of employees. ${ }^{105}$

Other applicable legislation is the Mine Health and Safety Act (No. 29 of 1996) ${ }^{106}$ and the Employment Equity Act (No. 55 of 1998). ${ }^{107}$ These Acts set out the requirements for substance testing, which confirm that some substances could have a negative impact on a workplace, and which validate substance testing as its consideration for security vetting. 
The employer's premises are not a 'private' but a 'public place'. It is submitted that employers may therefore implement rules that regulate the possession and use of cannabis in the workplace. This may, in the opinion of the authors, include a total prohibition on the use and possession of cannabis in the workplace. The draft 2020 Cannabis Bill makes provision for an individual to possess legally (in his or her private capacity) up to a $100 \mathrm{~g}$ of cannabis in a public place. Yeates however observes that, if a company has a workplace policy that prohibits any quantity of cannabis, it becomes a workplace rule. If an employee is in possession of any quantity in the workplace, it will then be viewed as a contravention of a workplace policy. ${ }^{108}$ This may lead to disciplinary action against the employee, not for being in possession of cannabis per se, but because of the breach of a workplace policy. Should the employee be in possession of more than $100 \mathrm{~g}$ of cannabis, it will constitute a crime in terms of the proposed legislation, and criminal prosecution will be instituted.

Terblanche, a legal specialist advocate in environmental health and safety, provided the following advice at a 2019 Occupational Health and Safety EXPO:

Until the state of being 'under the influence of cannabis' is medically defined, best practice advice for employers would be to make sure that the company rules set out a detailed written policy and procedure on alcohol and drug testing, with trade union input where applicable. The policy should state the reason for the information being outlined, namely safety and productivity, and should also indicate job categories and descriptions for which intoxication is not allowed. ${ }^{109}$

The authors posit that, as with alcohol abuse, the employer may take disciplinary action against an employee, without any testing, if the effects of cannabis are clearly observable. This can then be included in the employee's personnel file in terms of disciplinary action taken against the employee, which could be considered during the securityvetting process. Similarly, in the view of the authors, the employer may introduce a condition of employment that renders it obligatory to undergo regular medical testing if employment conditions justify such testing. This can also be applicable for security vetting to determine whether the applicant is suitable for the job from a security point of view. The authors submit that 'justifiable employment conditions' may be applicable in respect of certain occupations that involve operating heavy machinery, pilots, medical staff, or security services where employees are required to carry weapons or to be alert. Such circumstances may also include incidents where cannabis consumption poses a risk to the property of the employer or the safety of other employees and the public.

It is undisputed that an employee who is contractually bound to the employer during certain hours, has to adhere to all the employer's rules, regulations and policies during such hours. Sobriety requirements for cannabis must thus be treated in the same way as any other narcotic or alcohol-related tests or transgressions. In the end, it is the responsibility of the employer to ensure that policies and procedures are in place, which include and embrace cannabis-specific rules. 


\section{Making security-vetting decisions}

From the above, it is clear that cannabis, although legalised, may still have an adverse effect on the security competence of an individual. This then leads to the question as to what vetting decision-makers should decide regarding the security competence of the individual using cannabis. In answering this question, it is important to understand -

- firstly, what a vetting decision is;

- $\quad$ secondly, what vetting officers should consider when making vetting decisions on cannabis users;

- thirdly, what the challenges are in making these decisions; and

- lastly, which disqualifying and mitigating conditions vetting officers should consider.

\section{Vetting decisions}

In a study on financial misconduct, Kühn and Nieman posit that security-vetting decisions must be risk-based, and subsequently, the same can be said about the use of cannabis. ${ }^{110}$ The final vetting decision is made after an adjudication or evaluation process during which a risk analysis was done considering vulnerabilities and security threats. Ultimately, it is about determining the risk that an individual poses and making recommendations regarding certain important factors, such as integrity, loyalty, acts or omissions endangering security, and susceptibility to accepting bribes or to extortion or blackmail or to be influenced or compromised. ${ }^{111}$

During this process, a representative period of the person's life is evaluated to make a well-informed recommendation whether the person is eligible for access to classified information. ${ }^{112}$ Mdluli emphasises that the "whole person" phenomenon should be used during the assessment of a person's security competence. ${ }^{113}$ This implies that all information regarding a person is taken into consideration when making the final vetting decision. The decision further implies weighing up an applicant's strengths and weaknesses or favourable or unfavourable information about the person within the context of the type of occupation involved, such as carrying weapons or operating heavy machines. Mahlatsi also advocates the "whole person" approach. ${ }^{114}$

There are however several noteworthy challenges when dealing with cannabis in the workplace. The first relates to the detection of cannabis and the threshold for impairment. A drug test can detect the presence of $\triangle 9-\mathrm{THC}$, but unlike alcohol, there is no consensus on the threshold for impairment. ${ }^{115}$ Furthermore, the presence of $\Delta 9$-THC does not imply that an individual is impaired and it does not indicate how long ago the substance was consumed. ${ }^{116}$ Van Niekerk et al. observe that there are also other factors that could lead to a positive test for the substance, such as second-hand inhalation, the potency of the different strains of cannabis, and the individual's metabolism. However, despite these challenges and based on the above-mentioned discussion, some recommendations can be made for vetting personnel on what to consider when making vetting decisions in instances of cannabis use. 
Once there is an indication that an individual is using cannabis or had used cannabis, the first aspect is to determine the specific workplace requirements, such as a safe work environment where personnel work with heavy machinery, transport people and/ or, for example, carry weapons. The reason for this is that an overview of the relevant literature on cannabis consumption and its effect in the workplace identified a number of issues of which the most are human resource-related. ${ }^{117}$ These are a drop in attendance or productivity; disruptive or disorderly behaviour; an increase in accidents and safety violations; increased medical and insurance costs; and an increase in having to deal with substance abuse issues in the workplace. ${ }^{118}$ Van Niekerk emphasises the systemic nature of the influence of cannabis as it does not only affect the person's behaviour in the workplace, but also has a ripple effect throughout the organisation and even beyond that.

Closely linked to the workplace requirements is whether the employer has a cannabisspecific workplace policy in place. At organisational level, it should be determined whether a company has a policy that addresses the possession of cannabis in the workplace. It is also important to consider whether the policy is communicated effectively to all employees. In cases where organisations have a zero-tolerance policy and where there should be no presence of cannabis in the blood or urine of an individual, employees should be properly informed in this regard. ${ }^{119}$ It is therefore, recommended that organisations should at least have a policy or programmes that propagate abstinence from cannabis.

This is followed by determining the context of the use of cannabis. This indicates whether it was used in a recreational, medicinal, private or public context. In the case of medicinal use, it is important that the medication should be prescribed by a registered health care professional and that the final product consumed has undergone rigorous testing through clinical trials and is registered with the South African Health Products Regulatory Authority (SAHPRA). It is also worth noting that, at the time of writing, there was only one product approved for medicinal use in South Africa, while many of the claims of the benefits of cannabis use for medicinal purposes are without solid clinical evidence. Moreover, conduct that deviates from the approved medical direction for the use of the substance, such as grinding tablets and mixing it with tobacco in order to smoke it, will be a concern.

Likewise, the United States' National Oceanic and Atmospheric Administration (NOAA) identifies several factors the evaluator should follow when making vetting decisions of which the context is one. Decisions may include considering the age and maturity of the individual during the time of the conduct and whether the applicant participated voluntarily. ${ }^{120}$ For vetting decision-makers, it is the nature, extent and seriousness of the conduct of concern followed by the circumstances surrounding the conduct, including knowledgeable participation that need to be evaluated.

Next, the vetting officer needs to consider the frequency of use (occasional versus regular exposure) and determine the category of user as alluded to in Table 1. Although it is recommended not to look at frequency in isolation, research has revealed that frequent 
users of cannabis show a greater likelihood for violence than infrequent users. ${ }^{121}$ Once the frequency is known, the vetting officer must determine the duration of use followed by determining the quantity the individual consumes. The amounts used affect the impact cannabis has on an individual. Acute and chronic cannabis intoxication may impair a person's executive function as alluded to earlier. Closely linked to the quantity would be the cannabis load (frequency and quantity) the individual consumes. Information on cannabis load might be difficult to obtain, but if available, it could assist in reaching a more informed decision. The maker of a vetting decision must also consider the mode and products, as the way in which a person's body absorbs the substance as products with high potency (such as concentrates), which has the potential to lead to a significant increase in impairment, intoxication and the lasting effects of the substance, as observed by Gunn et al. ${ }^{122}$

The next step would be to determine the effect the consumption has on the individual, for example whether the person presents signs and symptoms of cannabis-dependence syndrome, and whether there are indications of adverse health consequences, such as impaired psychosocial and brain development, mental health and respiratory problems, cardiovascular disease, and an increase in, for example, motor vehicle accidents. The effect would specifically refer to the social (including financial and workplace behaviour), emotional and cognitive effect the substance has on the individual. The individual's reaction to intoxication is especially important in posts where executive functioning is required, such as flying a plane, but also in terms of everyday decisions, such as deciding whether you want to wear a blue or white shirt to work. This relates to his or her conduct or behaviour when intoxicated and the subsequent or coinciding nonadherence to workplace policies. Another area in which cannabis has an effect, is the productivity of an individual. ${ }^{123}$ As suggested above, concentration, emotional reaction, speed of reaction, and influence on memory are crucial factors here. It is therefore more important to determine what manifests in the intoxicated person's behaviour rather than only the presence of the substance in the person.

It is also important to determine the recency of the use, especially in the case where the individual displays behaviour that would have a negative impact on the vetting decision. ${ }^{124}$ This assumes that the more recent a behaviour has occurred, the more likely it is to occur again, especially if it coincided with a pleasurable experience.

There are other collateral factors that the vetting officer must consider, such as how the person had obtained the substance, whether there was illegal involvement, such as selling, cultivating, manufacturing, processing, distributing or using it outside the private domain or using it in public or attending work intoxicated.

After considering these factors, the vetting officer must determine the security risk that the individual poses. Security risk determination is a weighing process where the adjudicator will typically consider various factors. In the South African context, Mdluli suggests the following nine factors: 
- the nature, extent and seriousness of the conduct;

- the circumstances surrounding the conduct, or any knowledgeable participation;

- the frequency and recentness of the conduct;

- the individual's age and maturity at the time of the conduct;

- willingness to participate;

- the presence or absence of rehabilitation and other pertinent behavioural changes;

- the motivation for the conduct;

- $\quad$ the potential for pressure, coercion, exploitation or duress; and

- the likelihood of continuation or recurrence. ${ }^{125}$

The above factors relate closely to the considerations mentioned previously.

It is important to note that employees using cannabis at work may place the employer and other employees at risk if there is an incident where other employees get injured or even die due to an employee's use of cannabis (for example through the use of weapons or heavy machinery). Questions will then be asked regarding measures the employer had put in place to avert the occurrence of the incident; thus, placing the employer at risk for litigation or causing public embarrassment for the employer or organisation. This emphasises the necessity for an employer to have a well-written policy to provide regulatory certainty for both the employee and the organisation, and to consider these aspects in determining the risk.

From the above, it would be safe to postulate that the major concern with uncontrolled cannabis consumption and its unforeseen consequences is that using cannabis might contribute to the development of emotional, mental and personality disorders, which are likely to affect an individual's psychological, social and occupational functioning adversely. These are likely to lead to the exercise of questionable judgement, unreliability, failure to control impulses, and an increase in the risk of unauthorised disclosure of classified or sensitive information due to carelessness. If cannabis consumption coincides with known illegal activities and an unwillingness to comply with rules and regulations, it raises questions regarding an individual's willingness or ability to protect classified or sensitive information.

There are, however, still considerable uncertainties regarding the risks and benefits of cannabis use. It is worth noting that Laurens and Carstens suggest that the legal use of cannabis should be viewed from the same perspective as legal alcohol use and its effects on the workplace. ${ }^{126}$ Van Niekerk et al. postulate that organisations, which have strict health and safety measures in place, are likely to deal with the impact of personal cannabis use in the same way they are dealing with alcohol intoxication. ${ }^{127}$ See the reference above on workplace policies. The same can therefore be suggested for organisations that have strict measures in place with respect to security. 
All the above considerations should take place within the legal context, which implies that the individual's constitutional rights should not be limited while remaining within justifiable limits. There might also be instances where there is a risk that is manageable but with the necessary interventions. When a risk is identified, the organisation could therefore decide to manage the risk. Mdluli makes a number of suggestions for risk management. ${ }^{128}$ In the case of job applicants, a decision can be made to avoid or prevent the risk by refusing a security clearance and not appointing the individual. This would, however, depend on the nature of the job the incumbent will do, or it will depend on whether the organisation has a zero-tolerance policy for certain aspects. In the case of existing employees, the vetting authority may prevent the risk by withdrawing, downgrading or refusing a security clearance. It is important that due process should always be followed. The following Acts make provision for dealing with members viewed as unfit for employment in the particular organisation:

- $\quad$ section 14(7) of the Intelligence Services Act, 65 of 2002;

- $\quad$ sections 38, 39(2)(a) and (4)(a) of the Defence Act, 42 of 2002; and

- the South African Police Service Act, 68 of 1995.

Due to issues related to security clearance, a person may be redeployed in a less sensitive post or to another state department, or be discharged if he or she cannot be deployed elsewhere. This implies that the evaluator must consider both disqualifying and mitigating conditions when making the vetting decision. It is important to take note of some of these disqualifying or mitigating conditions.

Disqualifying conditions would, for example, be the illegal cultivation, manufacture, processing, sale or distribution of the substance. Furthermore, a formal diagnosis of substance dependency or abuse (e.g. CUD) made by a healthcare professional can be a disqualifying condition, especially if the affected individual is, for example, sent for rehabilitation or treatment and he or she does not successfully complete the programme or fails to follow the treatment advice. An indication by the individual that he or she intends to continue abusing the substance despite advice from management to desist from doing so, may also be a disqualifying condition. The conduct of the individual when under the influence of the substance in public, such as driving under the influence, aggressive behaviour, jeopardising the welfare and safety of others or other criminal incidents related to the misuse of the substance need to be considered. The findings of a study on acute cannabis consumption and motor vehicle collision risk conducted by Asbridge confirmed a marked increased risk of motor vehicle collisions. ${ }^{129}$

Another important disqualifying condition is the use of the substance at work or to report to work or duty when in an impaired or intoxicated condition. If the individual's conduct is of such a nature that exposing the conduct creates a vulnerability for the individual in terms of duress, manipulation or exploitation by any entity, such as a foreign intelligence service, crime syndicate or individuals, a disqualifying situation may result. All these instances may lead to an unfavourable determination. It is furthermore important to determine the motivation for the conduct and the likelihood of the continuation or reoccurrence of the conduct. 
There are several mitigating conditions that could lessen the security concerns. Illegal conduct committed a long time ago; an isolated event; an anomaly with no recurring pattern; a firm intention to refrain from such behaviour in future; or successful completion of a rehabilitation programme may demonstrate positive changes in behaviour and need to be considered in mitigation. In the latter case, a favourable prognosis by a registered healthcare professional could also contribute to mitigating the initial risk. Should the individual acknowledge a situation where he or she is informed of the adverse impact of his or her substance abuse, be able to provide evidence of actions taken to overcome the problem, and establishes a pattern of abstinence from the substance, this would constitute a mitigating situation. This would be reinforced further by providing an affidavit in which the individual undertakes to abstain from the substance and acknowledges that any future involvement with the substance may lead to denial or revoking of the security clearance. Further mitigation is applied in the event of information obtained from an unsubstantiated or unreliable source or where the organisation has an employee assistance programme, but no support was provided to the employee.

Weighing up the aggravating and mitigating conditions in the context of the 'whole person' determines the individual's risk profile. This risk can be either significant or insignificant, leading to the issuing of a security clearance. As stated elsewhere, as a rule of thumb, the same principles can be applied as to the use of alcohol as both are legal substances that can be misused. A combination of the adjudicative guidelines for substance abuse and drug involvement could therefore be used when making a vetting decision.

\section{Responsibility on employers}

Ultimately, the above-mentioned factors and/or considerations can be used to determine whether a security clearance would be issued, denied or revoked. However, the discussion above also highlights that organisations and employers have some form of social responsibility where an employee is likely to be affected negatively by cannabis use, whether these negative consequences are already present or foreseen to manifest in the near future. In the case of already employed personnel, employers need to support their employees who use, abuse or are addicted to cannabis, as employers are responsible for the well-being of their employees. It is recommended that there must be open communication where the use of cannabis can be discussed openly. ${ }^{130}$ It is of paramount importance that organisations rather follow a supportive approach where an intervention (assistance, such as counselling or progressive discipline) is initially implemented to protect the individual and his or her co-workers as opposed to following a punitive approach.

It is, furthermore, essential that employers ensure that their employees and prospective employees clearly understand their stance on the use of cannabis. This can be done through a workplace policy on cannabis. For example, employees must understand the meaning and implications of a 'zero tolerance' policy. There also needs to be a link to the occupational health and safety practitioners who must be able to do testing in the context of understanding the organisation's policies in this regard, which bio-matrix should be 
employed to test for cannabis, and the establishment of screening and confirmation cutoff concentrations for $\triangle 9$-THC. ${ }^{131}$ Likewise, it is also important to inform employees that the organisation is intolerant to employees not adhering to cannabis-related workplace policies due to its effect on the individual and the organisation. It is therefore advisable to rehabilitate before one terminates. Mdluli emphasises that all vetting processes, including remedial steps, be included in an employment contract or comprehensive vetting policy that is understandable and accessible to all employees. ${ }^{132}$

From the preceding discussion, it is also clear that, despite the recent legalisation of cannabis in South Africa, a vetting decision in the event of cannabis use by an applicant for a security clearance is not clear cut and involves a number of considerations. The considerations deduced from the literature should be included in an organisation's vetting policy to guide vetting decision-makers (adjudicators) in making a recommendation with respect to an individual's eligibility for access to classified information. It is thus important that the necessary governance be in place to ensure that applicants are aware that present and past conduct may influence their eligibility for access to classified information.

\section{Conclusion}

Mdluli emphasises that the ultimate determination of whether a person would be allowed access to classified information should be consistent with national security, but it must be "an overall common-sense determination, based on careful consideration [... in the context of the whole person". ${ }^{133}$ Therefore, the aim of the study reported here was to address the security-vetting dilemma caused by the reformed social attitudes regarding cannabis as well as the partial legalisation thereof in South Africa, which may have a potential negative outcome in the workplace. It is clear that each securityvetting dilemma presents a different set of risks and threats that need to be assessed within the framework of national legislation allowing the use of cannabis by an adult in private. Evidently, although the private use of cannabis at home has been legalised, it does not necessarily mean that employees are entitled to attend the workplace under the influence of the substance. In the case of an applicant using cannabis, the vetting process may disclose circumstances that may lead to security breaches, but may also provide an opportunity to evaluate an individual's conduct in context. Vetting decision-makers can thus not apply a blanket approach in making decisions on an applicant's suitability for access to classified information. Everyone should be evaluated individually, applying the 'whole person' concept, weighing up the aggravating and mitigating conditions in relation to the concern that may arise from the use of cannabis. The consumption of alcohol and the frequency thereof have been considered for decades in vetting decisions, and the authors advocate similar considerations for cannabis use.

It is important not to be blindsided by the applicant's constitutional rights, but also to consider the constitutional limitation clause that clearly mandates the limitation of a right where it is reasonable and justifiable considering the importance of the limitation, namely the protection of state security during security vetting. Furthermore, a job application is a voluntary process, and advertisements of government and other posts 
normally warn potential applicants that obtaining the necessary security clearance is a requirement for employment. ${ }^{134}$ The procedure usually includes written consent by the applicant. $^{135}$

On a practical level, the above-mentioned analysis clearly calls for employers to have cannabis-related workplace policies in place and to ensure that security-vetting institutions also have policies in place providing guidance to vetting practitioners in withdrawing or refusing a security clearance in relation to cannabis use. Employers should ensure that they have a cannabis-use policy available, which is accessible to employees; thus, emphasising awareness of the policy and its implications. Security vetting is intrusive and intended to uncover and analyse a combination of factors that can either enhance or mitigate an identified risk.

This article highlighted the necessity to train security-vetting investigators in exploring issues related to the use of cannabis to determine the effect of its use on the work environment in general and more specifically to establish an individual's eligibility for access to classified information and to view it within the context of current workplace policies.

Finally, making vetting decisions in the context of the now legalised cannabis is still filled with uncertainty. Therefore, this article aimed to stimulate further research into understanding both recreational and medicinal use of cannabis and its effect on the workplace and in situations where a determination must be made with respect to a person's eligibility for access to classified information. 


\section{ENDNOTES}

${ }^{1}$ Colonel (Dr) Petrus Bester is a senior lecturer in Industrial Psychology at the Faculty of Military Science, Stellenbosch University. Piet Bester grew up on a farm and during national service (conscription) he joined the South African Defence Force and obtained the degrees B Mil, Hons B Mil (Industrial Psychology) and a master' degree in Human Resources Management. He also completed the Doctoral Programme: Leadership in Performance and Change. During his military career, he completed the South African National Defence Force's Joint Senior Command and Staff Programme at the South African National War College, the South African National Defence College's Security and Defence Studies Programme and a Postgraduate Diploma in the Management of Security at the University of the Witwatersrand. Piet served as an army intelligence officer, intelligence officer at the Defence Intelligence Division, and in 2001 was re-employed as an industrial psychologist to the South African Military Health Service. Piet is currently a senior lecturer at the Stellenbosch University Faculty of Military Science. His research interests are leadership, integrity, performance enhancement, test construction, and national security.

${ }^{2}$ Lieutenant Colonel (Dr) Sonja Els is a senior lecturer in Mercantile and Public Law at the Faculty of Military Science, Stellenbosch University. About the authors: Sonja Els completed the B Iuris degree at North-West University (then PU vir CHO) after which she worked as public prosecutor at the Department of Justice for a period of five years. After obtaining the LLB degree, she worked at SASOL Secunda as commercial officer and later practised as an advocate of the High Court in Pretoria. In her military career at Defence Legal Services Division, she served as prosecution counsel and military law instructor at the School of Military Justice where she taught military law, trial advocacy, and law of armed conflict. She obtained the LLM and LLD degrees through the University of South Africa. Sonja is currently a senior lecturer at the Faculty of Military Science at Stellenbosch University. Her research interests are military law, law of peace operations, and law of criminal procedure.

${ }^{3}$ Republic of South Africa. Minimum Information Security Standards (MISS). Pretoria: Government Printing Works, 1996.

${ }^{4} \mathrm{R}$ Walton. "Balancing the insider and outsider threat". Computer Fraud \& Security November. 2006. 8.

${ }^{5} \mathrm{~S}$ Kühn \& A Nieman. "Can security vetting be extended to include the detection of financial misconduct?" African Security Review 26/4. 2017. 413-433. doi: 10.1080/10246029.2017.1294096; BD Mdluli. Fundamentals of security vetting in a democratic South Africa. Cape Town: BM Consultants, 2011, 3.

${ }^{6}$ JB Laurens \& PA Carstens. "Medicine and the law: Cannabis legalisation and testing for cannabis use in safety- and risk-sensitive environments". South African Medical Journal 110/10. 2020. 995-998.

${ }^{7}$ Staff Writer. "Everything you need to know about South Africa's weed laws - and what's coming next". BusinessTech. 7 June 2019. <https://businesstech.co.za/news/ business/322063/everything-you-need-to-know-about-south-africas-weed-laws-andwhats-coming-next/> Accessed on 11 December 2020; R van Niekerk, M Yeates \& P van Staden. "Legalization of cannabis: The real impact in the workplace". Online panel discussion at the 22nd Annual SIOPSA Conference Leading through Innovation: Navigating the New World of Work, 1-3 December 2020. <https:// youtu.be/NVwFIgSaJUk/> Accessed on 04 December 2020; Minister of Justice and Constitutional Development and Others v Prince (Clarke and Others Intervening); National Director of Public Prosecutions and Others v Rubin; National Director of Public Prosecutions and Others v Acton (CCT 108/17) 2018 ZACC 30. 
${ }^{8}$ Van Niekerk et al. op. cit.

${ }^{9} \mathrm{~J}$ Carnie. "Preserving security in a multi-tenanted hosting environment". Network Security 2010/4. 2010. 13.

${ }^{10}$ Mdluli op. cit., p. 78.

${ }^{11}$ Ibid., p. 79.

${ }^{12}$ Republic of South Africa op. cit., p. 13.

${ }^{13}$ South African Government. National Strategic Intelligence Act 39 of 1994. Pretoria: Government Printing Works, 1994, Section 1.

${ }^{14}$ MB Afolabi. “An insight into security vetting”. In LN Asiegbu, MB Afolabi \& DO Bodunde (eds), Unending frontiers in intelligence and security studies. Ado-Ekiti: Department of Intelligence and Security Studies, Afe Babalola University, 2017, 61-69.

${ }^{15} \mathrm{~K}$ Molapo. "Security vetting in the Department of Home Affairs". MA thesis. University of the Witwatersrand, 2017. <http://hdl.handle.net/10539/23041://uir.unisa.ac.za/ handle/10500/25690://youtu.be/NVwFIgSaJUk/>Accessed on 12 June 2016; Mdluli op. cit., p. 105.

${ }^{16}$ A Barnea. "Counterintelligence: Stepson of the intelligence discipline". Israel Affairs 23/4. 2017. 715-726. doi: 10.1080/13537121.2017.1333725

${ }^{17} \mathrm{~W}$ Wiese. Presentation on espionage case studies. Pretoria: Defence Intelligence Media Centre, 2020.

${ }^{18}$ Molapo op. cit., p. 1.

${ }^{19}$ Mdluli op. cit., p. 3.

${ }^{20}$ Defence Vetting Agency. "Welcome to the DVA". 2003. < https://www.gov.uk/government/ organisations/defence-vetting-agency $>$ Accessed on 4 January 2021.

${ }^{21}$ A Hazekamp. "The trouble with CBD oil". Medical Cannabis and Cannabinoids 1.2018. 6572. doi: $10.1159 / 000489287$; B Dhakal. "Is it worth legalizing cannabis uses for public? Harms and benefits of cannabis use". Research Gate, 2020. $<\mathrm{http} / \mathrm{www}$. nnzfsc.co.nz/> [https://www.researchgate.net/publication/344947474_Is_it_worth_ of_legalizing_cannabis_uses_for_public_Harms_and_Benefits_of_Cannabis_Uses Accessed on 3 January 2021; D Piomelli. "Editorial: Demistifying cannabis". Cannabis and Cannabinoid Research 4/1. 2019. 1-2.

${ }^{22}$ W Hall, E Hoch \& V Lorenzetti. "Cannabis use and mental health: Risks and benefits". European Archives of Psychiatry and Clinical Neuroscience 269. 2019. 1-3. doi: 10/1007/s00406-019-00986-2

${ }^{23}$ RL Gunn, ER Aston, AW Sokolovsky, HR White \& KM Jackson. "Complex cannabis use patterns: Associations with cannabis consequences and cannabis use disorder symptomatology". Addictive Behaviors 105. 2020. 1-8. doi: 10.1016/j. addbeh.2020.106329

${ }^{24}$ Staff Writer. "The most widely used drugs in South Africa". BusinessTech. ${ }^{24}$ September 2020. $<$ https://businesstech.co.za/news/lifestyle/435579/the-most-widely-used-drugs-insouth-africa/amp/> Accessed on 28 December 2020.

${ }^{25}$ V Singh. "The need for decriminalization of the use of cannabis - a comparative legal study". MA thesis. University of South Africa, 2019.

${ }^{26}$ G Ndondo. "Drug abuse: Youth in South Africa". Soul City Institute, n.d. $<\underline{\text { https://www. }}$ soulcity.org.za/resources/research/literature-reviews/soul-city-institute-drug-abuseyouth-south-africa.pdf/view/> Accessed on 23 January 2021.

${ }^{27}$ K Peltzer, S Ramlagan, BD Johnson \& N Phaswana-Mafuya. "Illicit drug use and treatment in South Africa". PubMed Central 45/113. 2010. 2221-2243. 
${ }^{28}$ M Amlung \& J MacKillop. “Availability of legalized cannabis reduces demand for illegal cannabis among Canadian cannabis users: Evidence from a behavioural economic substitution paradigm". Canadian Journal of Public Health 110. 2019. 216-221. doi: 10.17269/s41997-018-0160-4; D Shah, P Chand, M Bandawar, V Benegal \& P Murthy. "Cannabis induced psychosis and subsequent psychiatric disorders". Asian Journal of Psychiatry 30. 2017. 180-184. doi: 10.1016/j.ajp.2017.10.003; Hall et al. op. cit., p. 2; L Karila, P Roux, B Rolland, A Benyamina, M Reynaud, H-J Aubin \& C Lançon. "Acute and long-term effects of cannabis use: A review". Current Pharmaceutical Design 20/25. 2014. 4112-4118. doi: 10.2174/13816128113199990620

${ }^{29}$ L Dellazizzo, S Potvin, M Athanassiou \& A Dumais. "Violence and cannabis use: A focused review of a forgotten aspect in the era of liberalizing cannabis". Frontiers in Psychiatry 11. 2020. 1-11. doi: 10.3389/fpsyt.2020.567887

${ }^{30}$ Dellazizzo et al. op. cit., p. 2; Dhankal op. cit.; MM Sweeney, O Rass, C DiClemente, RL Schacht, HT Vo, MJ Fishman, JS Leoutsakos, MZ Mintzer \& MW Johnson. "Working memory training for adolescents with cannabis use disorder: A randomized controlled trial". Journal of Child \& Adolescent Substance Abuse 27/4. 2018. 211-226. doi: 10.1080/1067828X.2018.1451793

${ }^{31}$ Sweeney et al. op. cit.

${ }^{32}$ M Colizzi \& S Bhattacharyya. "Editorial: Cannabis: Neuropsychiatry and its effects on brain and behavior". Brain Sciences 10/11/. 2020. 1-5. doi: 10.3390/brainsci10110834

${ }^{33}$ Colizzi \& Bhattacharyya op. cit., p. 3.

${ }^{34}$ S Andréasson, P Allebeck, A Egnström \& U Rydberg. "Cannabis and schizophrenia: A longitudinal study of Swedish conscripts". Lancet 330. 1987. 1483-1486; Singh op. cit., p. 27.

${ }^{35}$ Fried et al., Hanson et al. \& Hooper et al., as cited in Sweeney et al. op. cit.

${ }^{36} \mathrm{~K}$ Mokwena. "Social and public health implications of the legislation of recreational cannabis: A literature review". African Journal of Primary Health Care \& Family Medicine 11/1. 2019. 1-6.

${ }^{37}$ Ibid., p. 2.

${ }^{38}$ Van Niekerk et al. op. cit.

${ }^{39}$ Mokwena op. cit., p. 1.

${ }^{40}$ Singh op. cit., p. 23.

${ }^{41}$ Ibid.

${ }^{42}$ Ibid.

${ }^{43}$ The authors made a summary of various studies as reported by Singh op. cit., pp. 24-28.

${ }^{44}$ Van Niekerk et al. op. cit.

${ }^{45}$ Dellazizzo et al. op. cit., p. 1.

${ }^{46}$ D Feingold, O Livne, J Rehm \& S Lev-Ran. “'Cannabis load': Measuring intensity of cannabis use and its association to cannabis use disorder". American Journal on Addictions (under review).

${ }^{47}$ Dellazizzo et al. op. cit., p. 6.

${ }^{48}$ Ibid., p. 1.

${ }^{49}$ LJ Schep, RJ Slaughter, P Glue \& P Gee. "The clinical toxicology of cannabis". New Zeeland Medical Journal 133/1523. 2020. 96-103.

${ }^{50}$ Ibid., p. 98.

${ }^{51}$ F Mouro, JA Ribeiro, AM Sebastiao \& N Dawson. "Chronic, intermittent treatment with a cannabinoid receptor agonist impairs recognition memory and brain network functional connectivity". Journal for Neurochemistry 147/1. 2018. 71-83.

${ }^{52}$ Dellazizzo et al. op. cit., p. 6.

${ }^{53}$ Feingold $o p$. cit.

${ }^{54}$ Gunn et al. op. cit., p. 6. 
${ }^{55}$ Hazekamp op. cit., p. 66.

${ }^{56}$ Gunn et al. op. cit., p. 6.

${ }^{57}$ Ibid.

${ }^{58}$ Colizzi op. cit., p. 2; Centre for Disease Control and Prevention. "How harmful is K2/Spice (synthetic marijuana or synthetic cannabinoids)?" 2021. <https://www.cdc.gov/ marijuana/faqs/how-harmful-is-k2-spice.html > Accessed on 28 May 2021.

${ }^{59}$ JC van Ours \& J Williams. "The effects of cannabis use on physical and mental health". Journal of Health Economics 31/4. 2012. 564-577. doi: 10.1016/j.jhealeco.2012.04.003

${ }^{60} \mathrm{Ibid}$, p. 576.

${ }^{61}$ Feingold $o p$. cit.

${ }^{62}$ S Lenton, VA Frank, MJ Barratt, GR Potter \& T Decorte. "Growing practices and the use of potentially harmful chemical additives among a sample of small-scale cannabis growers in three countries". Drug and Alcohol Dependence 192. 2018. 250-256. doi: 10.1016/j.drugalcdep.2018.07.040

${ }^{63}$ Gunn et al. op. cit., p. 6.

${ }^{64}$ Dellazizzo et al. op. cit., p. 2.

${ }^{65}$ Gunn et al. op. cit., p. 6.

${ }^{66}$ Mdluli op. cit., preface.

${ }^{67}$ South African Police Service Act 68 of 1995, Section 70.

${ }^{68}$ Defence Act 42 of 2002, Chapter 10, sections 37-41.

${ }^{69}$ S Riley, N Vellios \& C van Walbeek. "An economic analysis of the demand for cannabis: Some results from South Africa". Drugs: Education, Prevention and Policy 27/2/ 2019. 123-130. doi: 10.1080/09687637.2019.1581139

${ }^{70}$ Minister of Justice and Constitutional Development and Others v Prince (Clarke and Others Intervening); National Director of Public Prosecutions and Others v Rubin; National Director of Public Prosecutions and Others v Acton (CCT 108/17) 2018 ZACC 30; Drugs and Trafficking Act 140 of 1992; Medicines and Related Substances Act 101 of 1965.

${ }^{71}$ J Burchell. Principles of criminal law. Pretoria: Juta, 2013; Singh op. cit., p. 8.

${ }^{72}$ Customs and Excise Duties Amendment Act, 1922.

${ }^{73}$ Singh op. cit., p. 34.

${ }^{74}$ Medical, Dental and Pharmacy Act 13 of 1928.

${ }^{75}$ Weeds Act 42 of 1937.

${ }^{76}$ Medicines and Related Substances Act 101 of 1965.

${ }^{77}$ Pharmacies Act 53 of 1974.

${ }^{78}$ Criminal Procedure Act 51 of 1977.

${ }^{79}$ Drugs and Trafficking Act 140 of 1992.

${ }^{80}$ GN R509 of 2003, Schedule 7.

${ }^{81}$ S v Bhulwana, S v Gwadiso (CCT 12/95, CCT 11/95) 1995 ZACC 11; 1996 (1) SA 388; 1995 (12) BCLR 1579 [1].

${ }^{82}$ Medical Innovation Bill 2014 (rejected).

${ }^{83}$ Singh op. cit., p. 30.

${ }^{84}$ I Currie \& C de Waal. The Bill of Rights handbook ( $6^{\text {th }}$ ed.). Cape Town: Juta, 2015.

${ }^{85}$ Constitution of South Africa, 1996, section 36.

${ }^{86}$ Ibid., Section 36(1).

${ }^{87}$ Prince v President, Cape Law Society, 2001 BCLR 133, as cited in Singh op. cit., p. 36 (hereinafter referred to as "the first Prince case").

${ }^{88}$ Ibid., p. 37. 
${ }^{89}$ Prince v Minister of Justice and Constitutional Development and Others: Answering Affidavit of the Minister of Health, 2017 ZAWCHC; Rubin v National Director of Public Prosecutions and Others; Acton and Others v National Director of Public Prosecutions and Others (4153/2012) 2017 ZAWCHC 30, 20172 All SA 864 (WCC); 2017 (4) SA 299 (WCC); E Lubaale \& S Mavundla. "Decriminalisation of cannabis for personal use in South Africa". African Human Rights Journal 19/2. 2019. 819-842.

${ }^{90}$ As discussed by Singh op. cit., p. 44.

${ }^{91}$ Bernstein and others v Bester and others, NNO 1996 ZACC 2; 1996 (2) SA 751 (CC), as cited in Singh op. cit., p. 47.

${ }^{92}$ Singh op. cit., p. 48.

${ }^{93}$ Prince v Minister of Justice and Constitutional Development and Others; Rubin v National Director of Public Prosecutions and Others; Acton and Others v National Director of Public Prosecutions and Others.

${ }^{94}$ Ibid.

${ }^{95}$ C Parry, B Myers \& J Caulkins. "Correspondence: Decriminalisation of recreational cannabis in South Africa". The Lancet 393/10183. 2019. 1804-1805. doi: 10.1016/S01406736(19)30011-X; Lubaale \& Mavundla op. cit., p. 821.

${ }^{96}$ Prince v Minister of Justice and Constitutional Development and Others; Rubin v National Director of Public Prosecutions and Others; Acton and Others v National Director of Public Prosecutions and Others (4153/2012) 2017 ZAWCHC 30, 20172 All SA 864 (WCC); 2017 (4) SA 299 (WCC) [130].

${ }^{97}$ Lubaale \& Mavundla op. cit., p. 826.

${ }^{98}$ Draft Cannabis for Private Purposes Bill, 2020.

${ }^{99}$ M Steynvaart, M Wegerif \& P Vale. "Proposed cannabis law has serious shortcomings and must go back to the drawing board". Daily Maverick. 10 December 2020. $<\underline{\text { https:// }}$ www.dailymaverick.co.za/article/2020-12-10-proposed-cannabis-law-has-seriousshortcomings-and-must-go-back-to-the-drawing-board/> Accessed on 2 January 2021; A Richards \& A Wood. "Is the 2020 Cannabis Bill a flower among weeds or a weed among flowers?" International Law Office, 17 September 2020. $<$ https://www. internationallawoffice.com/Newsletters/Product-Regulation-Liability/South-Africa/ ENSafrica/Is-the-2020-Cannabis-Bill-a-flower-among-weeds-or-a-weed-amongflowers $>$ Accessed on 12 February 2021.

${ }^{100}$ Draft Cannabis for Private Purposes Bill, 2020.

${ }^{101}$ Ibid.

${ }^{102}$ Mokwena op. cit., p. 2.

${ }^{103}$ Laurens \& Carstens op. cit., p. 995.

${ }^{104}$ Occupational Health and Safety Act 85 of 1993.

${ }^{105}$ Ibid., Section 8(1).

${ }^{106}$ Mine Health and Safety Act 29 of 1996.

${ }^{107}$ Employment Equity Act 55 of 1998.

${ }^{108}$ Van Niekerk et al. op. cit.

${ }^{109} \mathrm{H}$ Terblanche. "Cannabis policies in the workplace - some re-thinking required?" Engineering News. n.d. $<$ https://www.engineeringnews.co.za/article/annabis-policies-in-theworkplace-some-re-thinking-required-2020-03-16/rep > Accessed on 18 December 2020.

${ }^{110}$ Kühn \& Nieman op. cit., p. 429.

${ }^{111}$ Mdluli op. cit., p 105.

${ }^{112}$ National Oceanic and Atmospheric Administration. "Adjudicative guidelines for determining eligibility for access to classified information". 24 March 1997. $<$ https://www.wrc. noaa.gov/wrso/security guide/adjudica.htm\#Drug\%20Involvement> Accessed on 8 January 2021. 
${ }^{113}$ Mdluli op. cit., pp. 105-106, 118.

${ }^{114}$ LW Mahlatsi. "An exploration of the chasm in the protection of classified information in South African government departments". MA thesis. University of South Africa, 2017. $<$ http://uir.unisa.ac.za/handle/10500/25690> Accessed on 18 January 2021.

${ }^{115}$ Ibid.

${ }^{116}$ Van Niekerk et al. op. cit.

${ }^{117} \mathrm{Ibid}$.

${ }^{118} \mathrm{Ibid}$.

${ }^{119}$ Ibid.

${ }^{120}$ National Oceanic and Atmospheric Administration op. cit.

${ }^{121}$ Feingold op. cit., p. 6.

${ }^{122}$ Gunn et al. op. cit., p. 6.

${ }^{123} \mathrm{Ibid}$.

${ }^{124}$ National Oceanic and Atmospheric Administration op. cit.

${ }^{125}$ Mdluli op. cit., p. 118.

${ }^{126}$ Laurens \& Carstens op. cit., p. 995.

${ }^{127}$ Van Niekerk et al. op. cit.

${ }^{128}$ Mdluli op. cit., pp. 32-33.

${ }^{129}$ Singh op. cit., p. 27.

${ }^{130}$ Van Niekerk et al. op. cit.

${ }^{131}$ Laurens \& Carstens op. cit., p. 995.

${ }^{132}$ Mdluli op. cit., p. 197.

${ }^{133}$ Ibid., p. 119.

${ }^{134}$ Ibid., pp. 29, 119.

${ }^{135}$ Ibid., p. 41. 